\title{
ПЕДАГОГИКА
}

\section{Управмение образованием}

\section{УДК 378.1}

\section{Проблема зон конфликтогенности образовательного пространства современного университета}

\section{Problems of conflict zones in the educational space of a modern university}

\author{
Панов Е.Г., Финансовый университет при Правительстве РФ, ЕРапоv@fa.ru
}

Panov E., Financial University under the Government of the Russian Federation, EPanov@fa.ru

DOI: 10.51379/KPJ.2021.147.3.001

\begin{abstract}
Статья подготовлена по результатам исследований, выполненных за счет бюджетных средств по государственному заданию Финуниверситета.
\end{abstract}

\begin{abstract}
Ключевье слова: образовательное пространство, зоны конфликтогенности, налогообложение, фискальная соичология, философия налогов.

Keywords: educational space, conflict zones, taxation, fiscal sociology, philosophy of taxes.

Аннотация. Актуальность статьи обусловлена практической необходимостью исследования зон конфликтогенности образовательного пространства. Выделяя отдельную проблему противоречий 6 содержании преподаваемых дисциилин, автор рассматривает предметную область подготовки специалистов в сфере налогообложения. Противоречивость его анализа с позиций экономики, права, социологии и философии отражается в конфликте преподавания соответствующих курсов. В практике ведущих университетов мира решением конфликта стало преподавание философии налогов, фискальной сочиологии, а также исследования налоговой культуры. Это позволило дополнить инструментальные характеристики налогов символическим анализом их роли в различных аспектах социальной реальности. В проведенном исследовании налогообложение представлено как способ конструирования социальной реальности, что акиентирует внимание на иенностных и мировоззренческих установках субъектов налогообложения. Построение образовательного процесса на этой основе способно внести гуманитарную составляющую в преподавание ряда учебных дисциплин. Это, в свою очередь, приведет к устранению определенных зон конфликтогенности образовательного пространства современного университета.
\end{abstract}

Abstract. The relevance of the article is due to the practical need to study the conflict zones of the educational space. Highlighting a separate problem of contradictions in the content of the taught disciplines, the author consider the subject area of training specialists in the field of taxation. In the practice of the world's leading universities, the solution to the conflict was the teaching of tax philosophy, fiscal sociology, as well as research on tax culture. This made it possible to supplement the instrumental characteristics of taxes with a symbolic analysis of their role in various aspects of social reality. In the study, taxation is presented as a way of constructing social reality, which focuses on the value and ideological attitudes of the subjects of taxation. Building the educational process on this basis is capable of introducing a humanitarian component into the teaching of a number of academic disciplines. This, in turn, will lead to the elimination of certain zones of conflict in the educational space of a modern university.

Введение. Образовательное пространство современного университета испытывает многообразные и разноплановые воздействия со стороны различных субъектов: общества, государства, обучающихся и их родителей, а также коллективов научно-педагогических кадров. Однако и сам процесс развития образовательной среды создает узлы 
напряженности, которые могут перерастать в зоны разрастающейся конфликтогенности. Прежде всего, это касается целостности образовательного процесса, которая обеспечивает качественную и всестороннюю подготовку специалистов.

Формально такой уровень подготовки обеспечивается грамотным составлением учебных планов и рабочих программ дисциплин, которые объединены посредством структурнологических схем построения всего процесса обучения. Тщательно выверенные соотношения аудиторной нагрузки и самостоятельной работы, правильно расставленные компетенции и детали организационного характера создают представление о достигнутой целостности в глазах вузовской администрации и контролирующих органов. Даже научнопедагогические работники могут удовлетвориться этими формализованными требованиями, которые в реальной практике преподавания необходимо наполнять различным «авторским» содержанием.

Реальное

осознание

целостности образовательного процесса оказывается доступным только самим обучающимся. Они воспринимают не то, как процесс должен быть организован, а как он сложился из разноплановых усилий всех субъектов, в том числе их собственными усилиями. Одним из узлов напряженности в этом случае выступает предметная определенность содержания образовательных дисциплин, которая своеобразно преподносится обучающимся специалистами в разных областях современного научного знания. Причем эти трактовки могут не только нести в себе существенные различия, но и напрямую противоречить друг другу. Такого рода узлы напряженности и зоны возможной конфликтогенности нашли одно из своих ярких проявлений в подготовке специалистов в области налогообложения.

Методология исследования. Для выработки методологии исследования необходимо учесть тот факт, что анализ налогообложения в современной научной литературе уже достаточно давно приобрел междисциплинарный характер. Налоги являются предметом таких специальных областей правовой науки, как финансовое и налоговое право. Наряду с этим, налогообложение стало предметом макроэкономического анализа, а также объектом государственного и муниципального управления. В течение длительного времени в российском образовании обсуждался вопрос о возможном выделении этой области знаний в самостоятельное направление подготовки, сочетающее в себе правовую, экономическую и управленческую составляющие, объединяемые политической и социальной ориентацией. Возможно, что сама противоречивость представлений о предметной определенности налогообложения не позволила принять подобное решение.

Конфликтогенный потенциал выявленного в ходе обсуждения данного узла напряженности был нивелирован инструментальным характером подготовки специалистов в области налогообложения. В конечном счете, принятая в современных российских университетах позиция направляет образовательный процесс в сферу налогового аудита, совместимого с подготовкой специалиста в области финансового учета и отчетности, дополняемого внесением в образовательный процесс современных форм и методов цифровизации. Однако такое решение привело к снижению теоретической оснащенности, что сближает уровни высшего и среднего специального образования в аспекте содержательной части основных курсов профильной подготовки. Особенно ярко эти проблемы проявляются при поступлении в университет для продолжения профильного обучения выпускников профильных колледжей.

Проблема зон предметной конфликтности преподаваемых дисциплин этой сферы образования анализировалась и в практике зарубежных университетов. Причем конфликт оказался многоуровневым, снятие напряженности в одном аспекте переводит конфликтную ситуацию в иную плоскость. Прежде всего, узлы напряженности выявились при соотнесении установленных позиций предметной определенности налогообложения в преподавании правовых и экономических дисциплин. Курсы финансового и налогового права связывают налогообложение с процессом формирования бюджета и трактуют налоги как инструмент расширения налогооблагаемой базы [12]. Для преподавания экономических дисциплин характерно рассмотрение налогов как внеэкономического способа изъятия средств из товарного оборота, нарушающего механизм рыночного регулирования. Это «необходимое зло» нуждается в постоянном контроле со стороны гражданского общества [10].

Разрешение конфликта политических и экономических позиций было осуществлено 
переводом рассмотрения проблемы в плоскость социально-политических отношений. Это нашло отражение в изучении и анализе практики финансовой политики различных государств. Она рассматривалась как постоянно формируемый и развивающийся социальный механизм соединения противоречивых интересов различных субъектов налогообложения [19]. Разработанные курсы финансовой политики стали основой преподавания политической философии или философии налогов в университетах, а также создания системы финансового образования (financial education) для широкой аудитории налогоплательщиков и членов их семей.

В отечественной научной литературе основная проблематика исследования налогообложения в аспекте современной политической философии получила обозначение как «философия налогов» [1, с.16-23; 4, с.61-65; 2, c.15-27]. На ее основе стали формироваться учебные курсы, прежде всего для уровня магистерской подготовки [9, с.295-319; 6, с.58168]. Однако дальнейшего развития и широкой популярности в российских университетах эта практика не получила. В определенном смысле это было обусловлено наличием еще одной зоны конфликтогенности в предметной области преподавания налогообложения, что было вызвано развитием фискальной социологии [15].

В противовес политической философии, отражающей позицию государства в сфере налогообложения, фискальная социология во главу угла поставила позицию налогоплательщика в системе его взаимоотношений с фискальными органами государства. Практическая значимость преподавания фискальной социологии была обусловлена анализом проблемы уклонения от уплаты налогов [8] и «ухода» части налогоплательщиков в «тень» [11]. В русле повседневной жизни гражданин может оказаться перед выбором - его насущные интересы не удовлетворяются установленными способами государственного регулирования и управления бизнес-процессами, а реальные проблемы решаются иным образом общественными фондами, религиозными общинами или теневыми структурами [3]. Поэтому налогоплательщик часть средств «уводит» из систем федеральных и местных налогов, в том числе и легальными способами. Затем эти средства направляются в те структуры, которые предлагают наиболее простые и эффективные меры решения повседневных проблем жизни граждан. В процессе формирования образовательного пространства выявленное противоречие в интересах фискальных органов и налогоплательщиков выразилось в противостоянии сформированных на этих позициях учебных курсов [18].

Апробированным способом разрешения этого уровня конфликтогенности образовательной среды стало включение в образовательный процесс особой области исследований, обозначаемых понятием «налоговая культура» (tax culture) [16]. В сложившейся системе преподавания налоговая культура стала рассматриваться как искусство социального управления, сравнимое с уровнем подготовки архитектора, а инструментальные практики налогообложения отнесли к уровню ремесла строителей. Поэтому уровень понимания налоговой культуры признается основополагающим, в том числе для рассмотрения таких узкопрофессиональных проблем «культуры налоговых выплат» (culture of taxation, tax-paying culture) [14]. Это выразилось в новых образовательных курсах, в рамках которых анализируются такие явления, как «налоговая этика» (tax morale) и «налоговая солидарность» (tax compliance) [13].

Наибольший эффект выработанные в рамках концепции налоговой культуры представления привнесли в рассмотрение трансформации структур налогообложения Германии, России и стран СНГ в конце прошлого века. Характерной чертой этого процесса было признано состояние налоговой системы, обозначаемое понятием «налоговый культурный шок» (tax culture shocks) [20]. Это состояние возникает при внесении в формирующуюся структуру налогообложения элементов, заимствованных из разнородных налоговых систем. Они не только вступают в противоречие друг с другом, но и оказываются несовместимыми с уже сложившимися традициям налоговой культуры трансформирующегося общества. Усугубляет это состояние тот факт, что решение о закреплении такого рода элементов в системе принимается законодательно без анализа самих процессов трансформации. Негативные последствия затрагивают всех субъектов налогообложения, вызывая непримиримые противоречия в развитии налоговой системы.

В этом отношении несомненный интерес представляет опыт Финансового университета при Правительстве РФ в реализации 
междисциплинарного курса «Формирование налоговой культуры». Он был создан усилиями пяти кафедр и предназначен для выпускников бакалавриата. Его преподавание имело целью дополнить и соединить в представлении обучающихся основные положения ранее освоенных ими курсов «Макроэкономики», «Налогового права», «Социологии налогов». Большое внимание в процессе обучения уделялось социальным аспектам истории налогообложения, а также формирующимся исследовательским позициям в рамках «философии налогов» [4]. Этот педагогический эксперимент сопровождался проведением социологического анализа динамики формирования интереса обучающихся и реализации их ожиданий при освоении отдельных частей и курса в целом [7].

Результаты проведенного эксперимента стали одним из оснований проводимого нами исследования. Прежде всего, следовало учесть, что эта часть образовательного процесса явилась дисциплиной по выбору. Поэтому основные ориентиры в еe формировании диктовались именно «ожиданиями» обучающихся выпускного курса. Их высокая заинтересованность проявилась в высоком уровне посещаемости занятий и уровнем требований к подготовленным преподавателями учебно-методическим материалам. Наибольший интерес обучающиеся проявляли к социальным аспектам и методам социологического анализа налогообложения и различных аспектов налоговой культуры. Также отмечался существенный рост интереса к истории налогов и философским проблемам налогообложения.

В качестве негативных аспектов приобретенного опыта преподавания следует отметить именно то, что стало анализироваться в дальнейших разработках этой сферы образовательного пространства. Обучающиеся отмечали отсутствие целостности в изложении предмета по причине «большой пестроты» позиций преподавателей, а также отсутствие преемственности в этих позициях. Развитие курса требовало усиления гуманитарной составляющей в преподавании всех дисциплин, особенно на старших курсах бакалавриата и в магистратуре. Интересно отметить, что эта составляющая уже давно была намечена и реализована в выделении символического аспекта многообразных социальных явлений и процессов.

В рамках исследования налогообложения символический анализ дополняет результаты понимания материально-вещественных компонентов налогов. В область представлений о налоговой культуре вводятся характеристики обыденной картины мира налогоплательщиков, их мировоззренческие и ценностные установки. Их следует соотносить с соответствующими положениями, принятыми на уровне господствующей государственной идеологии и официально формируемой системы потребностей и ценностей. Особенно важно проводить анализ конфликтов в области социальных и идейных отношений еще и потому, что они переходят в пространство современного университета, создавая в нем явные зоны конфликтогенности с позиций различных субъектов образовательного процесса.

Результатьл исследования. Практика отечественных и зарубежных университетов показывает, что введение курса налоговой культуры в образовательный процесс является доказанным способом снятия напряженности образовательного пространства подготовки обучающихся в области налогообложения. Дополнение гуманитарными составляющими их профильных компетенций позволяет осознать социальную роль, место и значение налогов в повседневной жизни граждан и политике государства. Обучающийся получает яркую и полную картину социальной реальности, в рамках которой он будет осуществлять свою деятельность, выдвигая социально значимые цели и ориентируясь на общечеловеческие ценности.

В представленном исследовании была предпринята попытка найти еще один вариант решения, который выражает и усиливает наметившуюся тенденцию к гуманитаризации в формировании образовательных программ современного университета. На современном этапе развития образовательного пространства зоны конфликтогенности перемещаются на все более высокий уровень теоретической подготовки. Существует осознание того, что обучающиеся будут проявлять наиболее обоснованные требования к мировоззренческим основаниям и методологии образовательного процесса. Причем в современном российском обществе еще не выработано однозначного понимания этих аспектов. Поэтому современные университеты будут вынуждены координировать собственные усилия в процессе формирования политики разрешения образовательных конфликтов и выработки стратегии гуманитарной подготовки. 
Предлагаемый вариант решения описанных выше проблем конфликтности предметной области преподавания затрагивает, прежде всего, особую сферу подготовки специалистов налоговой сферы. На основании анализа современной практики российских и зарубежных университетов, а также проведенных исследований истории налоговых систем можно сделать следующие выводы.

Во-первых, переход на позицию налогоплательщика демонстрирует сосуществование в обществе нескольких систем налогообложения. Каждая из них построена по принципу социальной сети, создающей определенную среду коммуникаций, в которой выражены жизненно важные ценности повседневности. Такого рода структуры конкурируют за право считаться реальными выразителями представлений о социальной справедливости. Налогоплательщик «голосует ногами», уклоняясь от «несправедливых» требований одной из систем и внося средства в поддержку существования другой. Субъектноориентированная методология социальных сред становится необходимым компонентом теоретического анализа.

Во-вторых, в налогообложении выражено конкретно-историческое представление о предметном воплощении его целостности. Уплата налога является ценностно рациональным поведенческим актом включения индивида в социальную общность. В истории налогообложения можно найти факты борьбы социальных групп за обязанность платить налоги, что влекло за собой признание за ними гражданских прав (борьба плебеев и патрициев в Древнем Риме) [5, с.161]. Отказ или уклонение от уплаты налогов становятся свидетельством социального протеста. Поэтому поводом для политических потрясений оказывались проблемы налогообложения, а революционные движения обретали собственную материальную основу в протестном сборе средств («American Revolution» в североамериканских колониях).

Третий вывод исследования формулирует предметную определенность, призванную объединить все уровни исследования налогообложения. Таким предметом может выступить процесс конструирования социальной реальности, выражающий основные традиции налоговой культуры. Основой формирования этих представлений является процесс генезиса конкретно-исторической общности и еe налоговых традиций. Наиболее интересным в этом плане является анализ существующих в обществе сетевых структур, не включенных в официально признанную государством налоговую систему. Несомненное значение в этом случае приобретает исследование структур самообложения современных религиозных общин и церковных организаций.

Заключение. На основании построенного таким образом исследования возможно внести кардинальные изменения в концепцию преподавания истории и теори налогообложения, экономической теории и налогового права. Центральное место в выстраиваемой архитектуре образовательного процесса должен занимать анализ идейных оснований сформированной в обществе налоговой культуры. Для этого выявляются существенные элементы современной картины мира, а также структуры системы ценностей и мировоззренческих ориентиров общества и личности.

Следует отметить, что эти усилия уже предпринимаются в сфере виртуальной реальности, которая отражает нашу действительность в предельно схематической форме. Одновременно процессы цифровизации образовательного пространства перемещают в эту реальность и обучающихся, и преподавателей. В условиях нарастающего «информационного шума» отсутствие целенаправленных усилий по систематизации и координации теоретических оснований преподаваемых дисциплин грозит полной дезориентацией обучающихся в ходе самостоятельной подготовки. Это ведет к их возрастающей демотивации по отношению к содержанию образования и ориентацией на формальные аспекты собственных успехов в обучении.

Гуманитаризация образования даже в отдельной области, каковой является подготовка специалистов в сфере налогообложения, может оказаться начальным этапом дальнейшей структурной трансформации всего образовательного пространства университета. В силу своей явно выраженной междисциплинарности изменения в преподавании теории и истории налогообложения, философии налогов и фискальной социологии повлекут за собой последствия в экономической и правовой подготовке обучающихся всех направлений. В образовательный процесс будут внедрены новые ракурсы сочетания макро- и микроэкономических аспектов в экономическом анализе, а также 
дополнение позиций государственно-правового регулирования элементами гражданско-правовых установок. Это, на наш взгляд, станет реальным методом устранения предметных зон конфликтогенности образовательного процесса современного университета и будет способствовать снятию ряда причин формирования узлов напряженности в его образовательном пространстве.

\section{Лumepamypa:}

1. Брызгалин А.В. Философия налогов / А.В. Брызгалин // Налоги и финансовое право. - 2009. - № 5. - C. 16-23.

2. Журавлева И.А. Философские основы системономической модели развития налоговой системы / И.А. Журавлева // Аудит и финансовый анализ. - 2019. - № 6. - С. 15-27.

3. Мазур Л.В., Батяев А.В. Налоговая нагрузка и теневая экономика / Л.В. Мазур, А.В. Батяев // Территория науки. - 2018. - № 5. - С. 98-102.

4. Панов Е.Г. «Философия налогов» (к постановке проблемы) / Е.Г. Панов // Вестник Финансовой академии. - 2009. - № 5(53). - С. 61-65.

5. Панов Е.Г. История налогов: Древний мир / Е.Г. Панов. - Москва: Ленанд, 2019. - 200 с.

6. Практическая философия: учебник для магистров экономических вузов // Лекция 4. «Философия налогов»: налогообложение как явление социальной жизни и теоретическая проблема. Москва: Проспект, 2017. - 465 с.

7. Силласте Г. Курс «Формирование налоговой культуры»: ожидания, реализация, пожелания. Социологическая диагностика качества преподавания учебной дисциплины и реализации студенческих ожиданий / Г. Силласте. - Москва: ФГОБУ ВПО «Финансовый университет при Правительстве Российской Федерации». 2011. - 74 с.

8. Уклонение от уплаты налогов. Проблемы и решения: монография для магистрантов, обучающихся по программам направления «Финансы и кредит». Москва: Юнити, 2015. - 383 с.

9. Философия в профессиональной деятельности: учебное пособие // Тема 8. Философия налогов. - Москва: Проспект, 2014. - 416 с.

10. Blocker A.W., Kotlikoff L.J., Ross S.A., Vallenas S.V. The True Cost of Social Security. // Tax Policy and the Economy. 2019. Vol. 33. - P. 131-163.
11. Fabbe K., Hartnett A.S., Monroe S.L. In the Shadows? Informal Enterprise in Non-Democracies. February 13, 2019 // Working Paper 19-083, Business Research for Business Leaders.

12. Gliniecka J. The Rule of Rational Management of Public Funds // Financial Law Review. 2019. Issue 16 (4). P. 1-16.

13. Lisi G. Tax morale, tax compliance and the optimal tax policy // Economic Analysis and Policy. 2015. Vol. 45. Issue c. - P. 27-32.

14. Livingston M.A. Tax and Culture. Convergence, Divergence, and the Future of Tax Law. Cambridge University Press, 2020.

15. Martin I.W., Mehrotra A.K., Prasad M. The New Fiscal Sociology: Taxation in Comparative and Historical Perspective. Cambridge University Press, 2009.

16. Nerré B. Tax Culture as a Basic Concept for Tax Policy Advice // Economic Analysis and Policy. 2008. Vol. 38. N 1. P. 153-167.

17. O'Neill M., Orr Sh. Taxation: Philosophical Perspectives. Oxford University Press, 2018.

18. Panova T.V., Panov E.G. Tax philosophy versus fiscal sociology: choice problem in teaching // SHS Web of Conferences, Volume 103 (2021) // International Scientific and Practical Conference "Solovyov Historical and Philosophical Readings. Russian and Foreign Experience in the System of Humanities Education: History, Modernity, Prospects" 2020, Moscow, Russia, December 3, 2020.

19. Rees-Jones A., Taubinsky D. Taxing Humans: Pitfalls of the Mechanism Design Approach and Potential Resolutions // Tax Policy and the Economy 2018. Vol. 32. Number 1. - P. 107-133.

20. Reut A.V. Legal measures of overcoming tax culture shocks and tax culture lags // Financial Law Review. 2019. N. 14 (2). - P. 77-95.

\section{References:}

1. Bryzgalin A.V. Philosophy of taxes / A.V. Bryzgalin // Tax and Financial Law 2009. - № 5. - P. 16-23.

2. Zhuravleva I.A. Philosophical foundations of a system-economic model of tax system development / I.A. Zhuravleva // Audit and financial analysis. - 2019. - № 6. P. 15-27.

3. Mazur L.V., Batyaev A.V. Tax burden and shadow economy Territory of Science / L.V. Mazur, A.V. Batyaev. - 2018. - № 5. - P. 98-102.
4. Panov E.G. "Philosophy of taxes" (to the problem statement) / E.G. Panov // Bulletin of the Financial Academy. - 2009. - № 5(53). - P. 61-65.

5. Panov E.G. History of Taxes: The Ancient World / E.G. Panov. - Moscow: Lenand, 2019. - 200 p.

6. Practical philosophy: a textbook for masters of economic universities // Lecture 4. "Philosophy of taxes": taxation as a phenomenon of social life and a theoretical problem - Moscow: Prospect, 2017. - 465 p.

7. Sillaste G. Course "Formation of tax culture": expectations, implementation, wishes. Sociological 
diagnostics of the quality of teaching the academic discipline and the realization of student expectations / G. Sillaste. - Moscow: FGOBU VPO "Financial University under the Government of the Russian Federation", 2011. $74 \mathrm{p}$.

8. Tax evasion. Problems and solutions: a monograph for undergraduates studying in programs of the direction "Finance and Credit". - Moscow: Unity, 2015. $383 \mathrm{p}$.

9. Philosophy in professional activity: textbook // Topic 8. Philosophy of taxes. - Moscow: Prospect, 2014. $416 \mathrm{p}$.

10. Blocker A.W., Kotlikoff L.J., Ross S.A., Vallenas S.V. The True Cost of Social Security // Tax Policy and the Economy. - 2019. - Vol. 33. - P. 131-163.

11. Fabbe K., Hartnett A.S., Monroe S.L. In the Shadows? Informal Enterprise in Non-Democracies. February 13, 2019 // Working Paper 19-083, Business Research for Business Leaders.

12. Gliniecka J. The Rule of Rational Management of Public Funds // Financial Law Review. 2019. Issue 16 (4). P. 1-16.

13. Lisi G. Tax morale, tax compliance and the optimal tax policy // Economic Analysis and Policy. 2015. Vol. 45. Issue c. - P. 27-32.
14. Livingston M.A. Tax and Culture. Convergence, Divergence, and the Future of Tax Law. Cambridge University Press, 2020.

15. Martin I.W., Mehrotra A.K., Prasad M. The New Fiscal Sociology: Taxation in Comparative and Historical Perspective. Cambridge University Press, 2009.

16. Nerré B. Tax Culture as a Basic Concept for Tax Policy Advice // Economic Analysis and Policy. 2008. Vol. 38. No 1. - P. 153-167.

17. O'Neill M., Orr Sh. Taxation: Philosophical Perspectives. Oxford University Press, 2018.

18. Panova T.V., Panov E.G. Tax philosophy versus fiscal sociology: choice problem in teaching // SHS Web of Conferences, Volume 103 (2021) // International Scientific and Practical Conference "Solovyov Historical and Philosophical Readings. Russian and Foreign Experience in the System of Humanities Education: History, Modernity, Prospects" 2020, Moscow, Russia, December 3, 2020.

19. Rees-Jones A., Taubinsky D. Taxing Humans: Pitfalls of the Mechanism Design Approach and Potential Resolutions // Tax Policy and the Economy 2018. Vol. 32. Number 1. - P. 107-133.

20. Reut A.V. Legal measures of overcoming tax culture shocks and tax culture lags // Financial Law Review. 2019. N. 14 (2). - P. 77-95.

13.00.08 -Теория и методика профессионального образования

\section{Сведения об авторе:}

Панов Евгений Генрихович (г. Москва, Россия), кандидат философских наук, доцент Департамента гуманитарных наук Финансового университета при Правительстве Российской Федерации, e-mail: EPanov@fa.ru

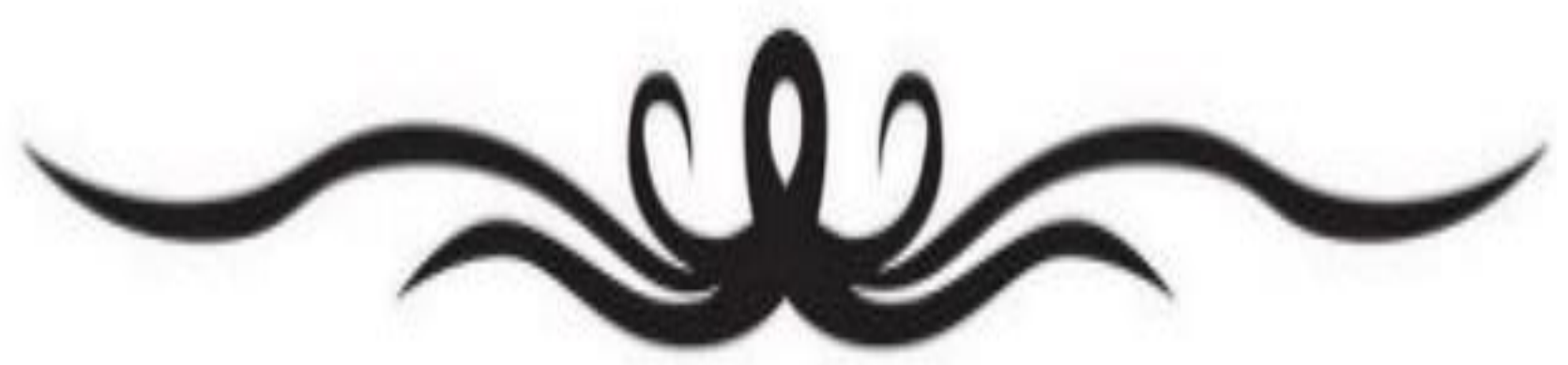

